\title{
ASSESMEN SUBYEKTIVITAS PENGOLAHAN HASIL PANEN DENGAN SISTEM MEKANISASI YANG ERGONOMIS
}

\author{
Ahmad Hanafie ${ }^{13}$, Andi Haslindah ${ }^{21}$, Saripuddin Muddin ${ }^{3)}$, Awaluddin Yunus ${ }^{4)}$ \\ Program Studi Teknik Industri, Universitas Islam Makassar ${ }^{11,2)}$, Teknik Mesin Universitas Islam Makassar ${ }^{3 /}$ \\ Program Studi Agribisnis Universitas Islam Makassar ${ }^{4 /}$ \\ JI. Périntis Kemerdekaan KM 9 No.29 Kampus UIM TIpn 0411-588-167 \\ Email:ahmadhanafie.dty@uim-makassar.ac.id
}

\begin{abstract}
ABSTRAK
Rancangan hasil penelitian yang telah dilakukan yaitu rancangan kursi pada mesin combine harverter yang dapat dikendarai oleh pengguna, yang sebelumnya penelitian hanya di kendalikan dangan cara operator berada di bagian belakang alat combine harverter tesebut. Mesin Combine Harverter yang dirancang ini akan dilkukan asessemen terhadap subyektivitas pekerja. Dari dua puluh tujuh parameter analisis yang digunakan apakah alat tersebut dapat mereduksi faktor-faktor kelelahan yang terjadi sata melakukan aktivitas pekerja. Pada penelitian ini fokus pada bagian perancangan kursi bagian operator atau pengguna. Metode Penelitian dilakukan identifikasi variabel penelitian yang akan menjadi dasar dalam penentuan langkah-langkah penelitian serta variabel penelitian adalah jenis-jenis keluhan yang dirasakan pada rancangan kursi pada mesin combine harverter. Hasil penelitian menunjukkan bahwa Hasil Assesmen Subyektivitas / keluhan-keluhan yang terjadi pada tubuh pekerja dalam menggunakan rancangan kursi pada mesin combine harverter yaitu $44 \%$ masih merasakan kondisi agak sakit dan sakit pada bagian tubuh penggunan terutama pada bagian pokong, pantat karena kursi yang dirancang tidak menggunakan lapisan pada kursi tersebut, sedangkan posisi kaki kanan yang tentunya masih tinggi beban yang dirasakan saat menjalankan aktivitas. Sedangkan Assesmen rata-rata tingkat keluhan menunjukkan berada dalam batas normal yaitu 1,40-1,83, yang artinya pengguna kursi/tempat duduk pada mesin combine harverter dalam kondisi aman dan nyaman digunakan.
\end{abstract}

Kata Kunci: Subyektivitas, Assesmen, Ergonomi

\section{ABSTRACT}

The result of the research that has been done is that the combination that can be driven by the user, the previous research is only controlled by the operator's method on the back of the device that combines the converter. The designed Combine Harverter machine will be assessed for worker subjectivity. Of the twenty-seven analysis parameters used are factors that can be used to do work. At this stage the focus is on the part of the operator or operator. The research method is a research variable that will be the basis for determining the steps of the study and research variables, namely the types that influence the combine harverter machine. The results showed that the Subjectivity Assessment Results / complaints that occurred in the body of the worker in using the seat design on the combine harverter machine that was $44 \%$ still felt a bit sick and sick in the body part, especially in the buttocks, but because the designed chair did not use the layer in the chair, while the position of the right foot which is of course still a high burden is felt when carrying out activities. While the average assessment of the level of complaint shows that it is within the normal range of $1.40-1.83$, which means that the user of the seat / seat on the combine converter machine is safe and comfortable to use.

Keywords: Subjectivity, Assessment, Ergonomics 


\section{PENDAHULUAN}

Penggunaan alat kerja dalam proses pengerjaan sudah lama di lakukan oleh manusia untuk mengelolah hasil agar lebih cepat. Perkembangan teknologi tidak bisa dipungkiri baik secara semi otomatis, ke otomatis hingga ke sifat yang serba digital yang dikendalikan oleh manusia besi / robot. Begitu pula proses pengelohan yang ada di area sawah dari cara pengelolaan hasil panen yang cara tradisional sampai ke model thresher, lalu ke model yang moderen yaitu dengan menggunakan mesin yang serba cepat dalam menyelesaikan persoalan-persolan pengolahan hasil panen yang cepat dan berkualitas.

Penyelesaian pekerjaan yang sesuai dengan kondisi pekerja dengan alat yang digunakan itu Ergonomi yang mampu mereduksi faktor-faktor kelelahan yang sering terjadi pada pengguna alat tesebut. Banyak produk dirancang tidak memperhatikan aspek-aspek manusia yaitu dimensi tubuh, subyektivitas, konsumsi energi, penggunaan otot atau biomekanikal. Analisa Subyektivitas adalah salah satu bagian dari ergonomi yaitu keluhan-keluhan yang dirasakan pada saat melakukan aktivitas pekerjaan. Keluhan-keluhan yang terjadi yang disebabkan oleh posisi kerja atau mesin atau alat yang tdak sesuai dengan dimensi tubuh pekerja.

Rancangan hasil penelitian yang telah dilakukan yaitu rancangan kursi pada mesin combine harverter yang dapat dikendarai oleh pengguna, yang sebelumnya penelitian hanya di kendalikan dangan cara operator berada di bagian belakang alat combine harverter tesebut. Mensin Combine Harverter yang dirancang ini akan dilkukan asessemen terhadap subyektivitas pekerja. Dari duapuluh tujuh parameter analisis yang digunakan apakah alat tersebut dapat mereduksi faktor-faktor kelelahan yang terjadi sata melakukan aktivitas pekerja. Pada penelitian ini fokus pada bagian perancangan kursi bagian operator atau pengguna.

\section{METODE PENEUTIAN}

\section{Populasi dan Sampel Penelitian}

Populasi dan sampel penelitian adalah penggunan mesin combine harverter yang ada di Kabupaten Pinrang. Dan pengambilan sampel untuk mesin combine harverter yaitu bagian kursi, bagian penginputan hasil pengolahan, bagian perontokan dan bagian pengumpulan dari hasil pengolahan hasil panen.

\section{Jenis dan Sumber Data}

Jenis dan sumber data yang diperlukan dalam penelitian ini:

- Data primer yaitu data yang diperoleh yaitu pertama, Observasi mengadakan penelitian atau pengamatan pada obyek penelitian berupa pengamatan langsung terhadap pengguna mesin combine harveter. Kedua Interview melakukan wawancara kepada para pengguna pengguna mesin combine harveter.

- Data skunder yaitu data yang diperoleh dari jurnal, buku dan penelitian-penelitian sebelumnya dari berbagai sumber bacaan yang berkaitan dengan penelitian.

Identifikasi variabel penelitian

Dalam penelitian dilakukan identifikasi variabel penelitian yang akan menjadi dasar dalam penentuan langkah-langkah penelitian serta variabel penelitian adalah jenis-jenis keluhan yang dirasakan pada rancangan kursi pada mesin combine harverter.

Identifikasi Sampel Penelitian

Pada penelitian ini, populasi yang menjadi obyek penelitian adalah penggunan combine harverter. Adapun sampel yang akan diambil sekitar 35 sampel, dengan proporsi jumlah kuesioner yang dianggap benar $95 \%$ dan Serta tingkat ketelitian yaitu $5 \%$

Rancangan Survei dan Validitas Data Penelitian

Pengumpulan data kualitatif dilakukan nordic body untuk mengetahui keluhan-keluhan pengguna mesin combine harverter untuk mengetahui apa keluhan-keluhan yang dirasakan oleh penggunan mesin combine harverter adapun skala asessmen tingkat keluhan dan Jenis keluhan seperti tabel dibawah ini: 
Tabel 1. Skala assesmen tingkat keluhan

\begin{tabular}{lc} 
Tingkat Keluhan & $\begin{array}{c}\text { Skala } \\
\text { Asessemen }\end{array}$ \\
\hline Tidak Sakit & 1 \\
Agak Sakit & 2 \\
Sakit & 3 \\
Sangat sakit & 4 \\
\hline
\end{tabular}

Tabel 2. Jenis-jenis keluhan

\begin{tabular}{l} 
No. \\
\hline 1 Sakit/kaku bagian atas dan bawah \\
2 Sakit dibahu kiri \\
3 Sakit dibahu kanan \\
4 Sakit pada lengan atas kiri \\
5 Sakit dipunggung \\
6 Sakit pada lengan atas kanan \\
7 Sakit pada pinggang \\
8 Sakit pada bokong \\
9 Sakit pada pantat \\
10 Sakit pada siku kiri \\
11 Sakit pada siku kanan \\
12 Sakit pada lengan bawah kiri \\
13 Sakit pada lengan bawah kanan \\
14 Sakit pada pergelangan tangan kiri \\
15 Sakit pada pergelangan tangan kanan \\
16 Sakit pada tangan kiri \\
17 Sakit pada tangan kanan \\
18 Sakit pada paha kiri \\
19 Sakit pada paha kanan \\
20 Sakit pada lutut kiri \\
21 Sakit pada lutut kanan \\
22 Sakit pada betis kiri \\
23 Sakit pada betis kanan \\
24 Sakit pada pergelangan kaki kiri \\
25 Sakit pada pergelangan kaki kanan \\
26 Sakit pada kaki kiri \\
27 Sakit pada kaki kanan \\
\hline
\end{tabular}

\section{HASIL DAN PEMBAHASAN}

\section{Hasil Assesmen tingkat keluhan}

Penelitian nordic body map yang telah dilakukan dengan 35 responden dan 27 jenis pertanyaan atau tingkat keluhan-keluhan yang dirasakan oleh pengguna mesin combine harverter tersebut adapun hasil penelitian pada gambar 1. 


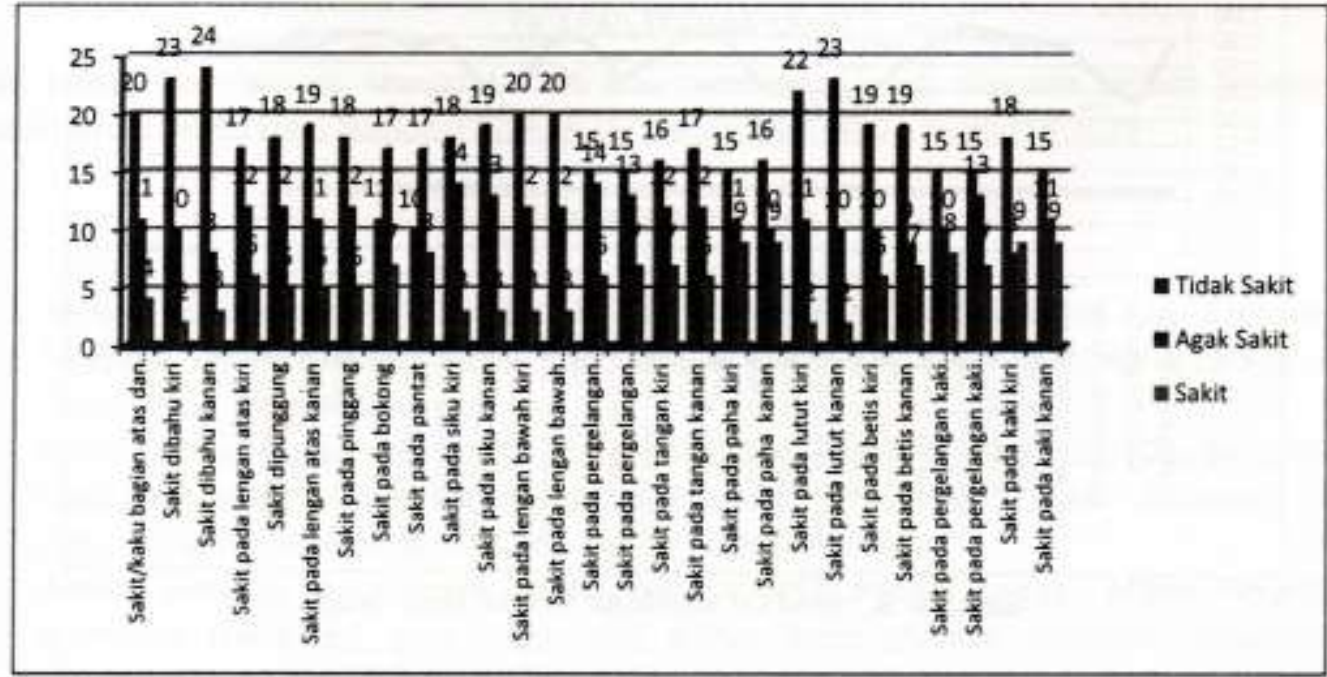

Gambar 1. Hasil assesmen tingkat keluhan

Berdasarkan gambar 1. Menunjukkan hasil asessemen tingkat keluhan pengguna mesin perontok padi khususnya pada bagian kursi dimana nilai assesmen yang menyatakan merasakan tidak sakit saat menggunakan kursi yaitu $56 \%$ yaitu jenis keluhan pada bagian bagian atas/bawah, bahu kiri, bahu kanan, dipunggung, lengan atas kanan, lengan atas kirim siku kiri, siku kanan, lengan bawah kiri, lengan bawah kanan, lutut kiri, lutut kakan, betis kiri, betis kanandan kaki kiri, sedangkan agak sakit dan sakit berkisar $44 \%$ jenis keluhan pada bagian lengan atas kiri, bokong, pantat, peregelangan tangan kiri, pergelangan tangan kanan, tangan kiri, tangan kanan, paha kanan, paha kiri, pergelangan kaki kiri, pergelangan kaki kanan, dan kaki kanan.

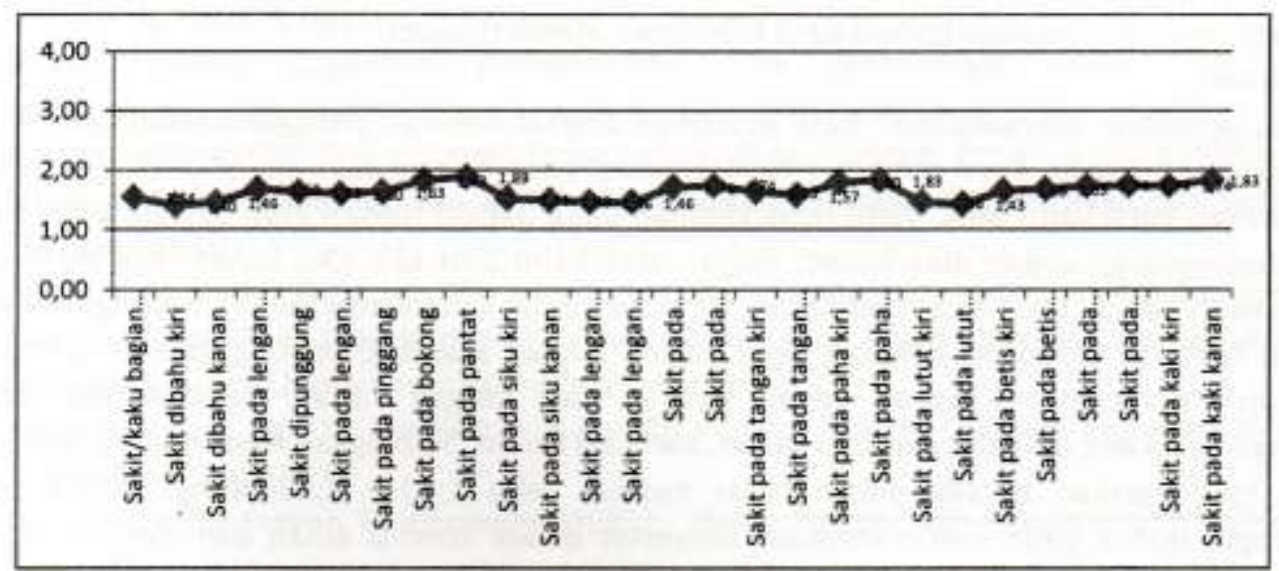

Gambar 2. Rata-rata asesmen skala tingkat keluhan

Rata-rata tingkat jawaban Hasil oleh penggunan yang mampu menggambarkan apa yang diinginkan oleh pengguna. Rata-rata Asesmen skala tingkat keluhan yaitu 1,40-1,83 menujukkan bahwa tingkat keluhan yang diterima pada tubuh dalam kondisi yang normal. Hal tersebut menujukkan bahwa pengguna merasa nyaman dan aman dalam melakukan aktivitas. 


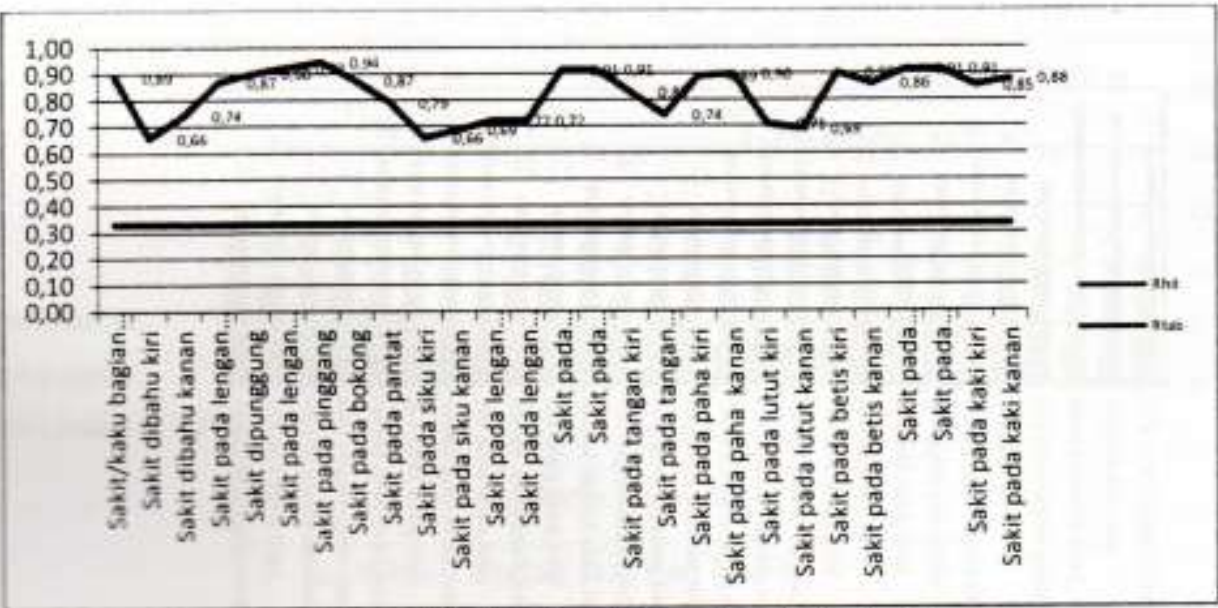

Gambar 3. Hasil uji validitas Nordic Body Map

Gambar 3 Menunjukkan bahwa uji validitas digunakan untuk mengetahui jenis keluhan kuesioner yang telah diisi oleh responden dapat mewakili atau menggambarkan apa yang yang dirasakan oleh pengguna terhadap mesin yang digunakan. Uji validitas ini menggunakan data tingkat keluhan pada bagian tubuh responden yang diperoleh lewat koesioner Norbodic Body Map. Pengujian validitas ini menggunakan perhitungan PEARSON dengan bantuan software MS EXCEL 2010. Suatu variabel dikatakan valid jika $r$ hitung yang dapat bernilai lebih besar dari pada nilai $r$ tabel $d f=N-2$. Jumlah pengamatan sebesar $35, \mathrm{df}=35-2=33$, dengan menggunakan tingkat ketelitian $5 \%$ diperoleh $\mathrm{r}_{\text {tatel }}$ $=0.334$.

Uji reliabilitas digunakan untuk melihat tingkat konsistensi dari respon terhadap variabel yang ada. Uji reliabilitas yang dilakukan setelah perancangan kursih yang digunakan pengguna. Maka diperoleh hasil sebagai berikut. Dari output diatas bahwa nilai alpha $=0.9611$, lebih besar daripada 0,334 , jadi dapat disimpulkan bahwa hasil kuesioner adalah reliabel.

Pembahasan

Hasil penelitian menunjukkan hasil assesmen tingkat keluhan pengguna mesin perontok padi khususnya pada bagian kursi dimana nilai assesmen yang menyatakan merasakan tidak sakit saat menggunakan kursi yaitu $56 \%$ yaitu jenis keluhan pada bagian bagian atas/bawah, bahu kiri, bahu kanan, dipunggung, lengan atas kanan, lengan atas kirim siku kiri, siku kanan, lengan bawah kiri, lengan bawah kanan, lutut kiri, lutut kakan, betis kiri, betis kanandan kaki kiri, sedangkan agak sakit dan sakit berkisar $44 \%$ jenis keluhan pada bagian lengan atas kiri, bokong, pantat, peregelangan tangan kiri, pergelangan tangan kanan, tangan kiri, tangan kanan, paha kanan, paha kiri, pergelangan kaki kiri, pergelangan kaki kanan, dan kaki kanan. Sedangkan Assesmen rata-rata tingkat keluhan menunjukkan berada dalam batas normal yaitu $1,40-1,83$, yang artinya pengguna kursi/tempat duduk pada mesin combine harverter dalam kondisi aman dan nyaman digunakan. Namun masih perlu adanya perbaikan pada duabelas posisi tubuh yang perlu diperhatikan.

\section{KESIMPULAN}

Hasil penelitian menunjukkan bahwa Hasil Assesmen Subyektivitas/keluhan-keluhan yang terjadi pada tubuh pekerja dalam menggunakan rancangan kursi pada mesin combine harverter yaitu $44 \%$ masih merasakan kondisi agak sakit dan sakit pada bagian tubuh penggunan terutama pada bagian pokong, pantat karena kursi yang dirancang tidak menggunakan lapisan pada kursi tersebut, sedangkan posisi kaki kanan yang tentunya masih tinggi beban yang dirasakan saat menjalankan aktivitas. Sedangkan Assesmen rata-rata tingkat keluhan menunjukkan berada dalam batas normal yaitu $1,40-1,83$, yang artinya pengguna kursi/tempat duduk pada mesin combine harverter dalam kondisi aman dan nyaman digunakan. 


\section{UCAPAN TERIMA KASIH}

Ucapan terima kasih kepada Menristek Dikti atas pembiayaan yang diberikan kepada peneliti melalui penelitian Program Strategi Nasional (STRANAS) pendanaan tahun anggaran 2018

\section{DAFTAR PUSTAKA}

[1] Ahmad Hanafie (2007), Modifikasi Helm Standar Kendaraan Roda Dua Yang Ergonomis Bagi Penguna Telpon Seluler, Jurnal IItek, Vol. II, Nomor 4, April 2007, Hal 313-319, Fakultas Teknik Univ. Islam Makassar.

[2] Ahmad Hanafie, Darmulia (2014), Pengembangan Mesin Perontok Padi (Combine Harverter) yang Ergonomis Untuk Meningkatkan Produksi, Prosiding Seminar Nasional Teknologi Industri ll Atim 2014, ISSN. 978-602-14822-16, Hal. 346-381.

[3] Ahmad Hanafie, A.Haslindah, Muh. Fadhli (2015), Pengembangan Mesin Perontok Padi (Combine Harverter) yang Ergonomis Untuk Meningkatkan Produksi, Majalah Teknik Industri, Vol. 22/No.1/Juni 2015, ISSN. 1410-7015, Hal. 67-72.

[4] Ahmad Hanafie, A.Haslindah, Muh. Fadhli (2015), Pengembangan Mesin Perontok Padi (Combine Harverter) yang Ergonomis Untuk Meningkatkan Produksi, Prosiding Seminar Nasional Tahunan Teknik Mesin Indonesia-XIV, Banjarmasin, 7-8 Oktober 2015.

[5] Ahmad Hanafie, Hammada Abbas, Lawalenna, Sumarni Hamid (2016), Study Of Vehicles Utilities And Load-Unloading Facilities Of City Public Transport Based On Ergonomics Assessment, International Journal of Advances in Scientific Research and Engineering (ijasre.net) Volume-1, Issue-3, December-2015.

[6] Ahmad Hanafie, Andi Haslinda, Saripuddin Muddin, Awaluddin Yunus (2018), Implementation of Ergonomics In The Management of Crop Yields Using Combine Harvesters, International Journal of Advances in Scientific Research and Engineering, Volume-4, Issue-8, Agustus - 2018.

[7] Astika (2007), Ergonomi Pertumbuhan Dan Peranannya Dalam Pembangunan, http://www.baliheag.org

[8] Eko Nurmianto (2007), Ergonomi, konsep dasar \& aplikasinya, Penerbit Guna Widya, Jakarta.

[9] Iftikar Z. Sutalaksana; Ruhana A; John H. T (2006), Analisa dan Perancongan Sistem Kerja. Jurusan TI ITB.

[10] Muh. Yani Syafei Dr,H.,ST.,MT, (2007), Aplikasi Konsep Ergonomi Dalam Pengembangan Design Produk Akan Memberikan Nilai Jual Produk yang Tinggi dan dan Keunggulan Bersaing. Seminar Nasional Ergonomics in product Development.

[11] Noor Fitrihana, (2007), Memperbaiki Kondisi Kerja di Industri Garmen, Ergonomi Kerja, B4D3 Consultants, hal 1-12.

[12] Karl T. Ulrich, Steven D. Eppinger (2001), Perancangan dan Pengembangan Produk, Mc Graw Hill

[13] Roche; Davila, USA (1972), Dalam bukunya Wignjosoebroto, Sritomo Sritomo (2000), Ergonomi, Studi Gerak \& waktu. Penerbit Guna widya, Jakarta.

[14] Sritomo Wignjosoebroto, (2008), Ergonomi, Studi Gerak \& waktu. Penerbit Guna widya, Jakarta.

[15] Sritomo Wignjosoebroto, Srigunani, Ahmad Hanafie. (2003), Modifikasi mesin perontok Padi yang Ergonomis. PEl, Yogyakarta.

[16] Sudjana (1989). Metoda Statistika. penerbit Tarsito, Bandung. 